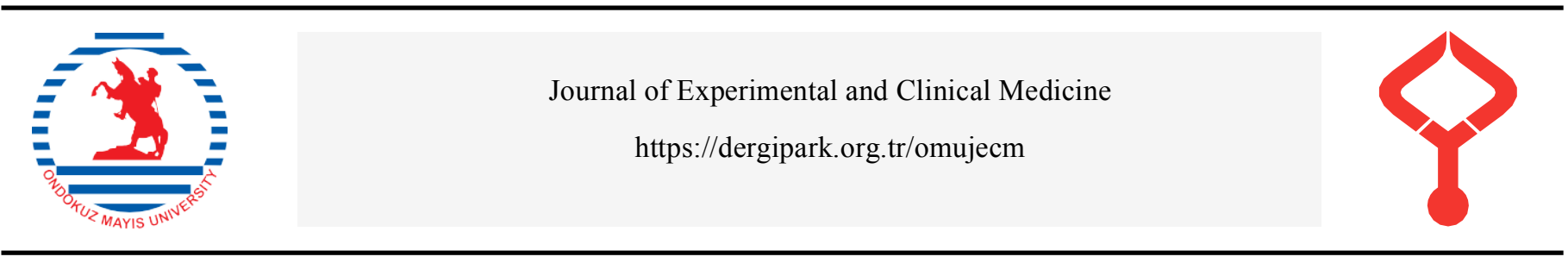

Research Article

$\mathrm{J}$ Exp Clin Med

2021; 38(2): 197-203

doi: $10.52142 /$ omujecm.38.2.26

\title{
Volumetric analysis of the brain structures of children with down's syndrome: A 3D MRI study
}

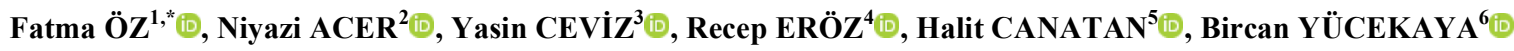

${ }^{1}$ Department of Anatomy, Faculty of Medicine, Hatay Mustafa Kemal University, Hatay, Turkey

${ }^{2}$ Department of Anatomy, Faculty of Medicine, Arel University, İstanbul, Turkey

${ }^{3}$ Department of Anatomy, Graduate School of Health Sciences, Erciyes University, Kayseri, Turkey

${ }^{4}$ Department of Medical Genetics, Faculty of Medicine, Düzce University, Düzce, Turkey

${ }^{5}$ Department of Medical Biology, Faculty of Medicine, Erciyes University, Kayseri, Turkey

${ }^{6}$ Department of Physiotherapy and Rehabilitation, Faculty of Health Science, Ondokuz Mayis University, Samsun, Turkey

\begin{tabular}{ccccc}
\hline Received: 25.02 .2021 & $\bullet$ & Accepted/Published Online: 30.03 .2021 & $\bullet$ & Final Version: 14.03 .2021 \\
\hline
\end{tabular}

\begin{abstract}
Down's syndrome (DS) is one of the most common genetic causes of mental and cognitive retardation. In fact, it results in a number of characteristic neuropsychological and physical symptoms, including mental retardation. The aim of this study was to compare the brain structure volumes of children with DS to those of healthy children using MRI Studio in order to investigate whether there exists correlation between the developmental stages of DS and the results of both the Denver II Developmental Screening Test and magnetic resonance imaging (MRI) quantitative analysis. Five children diagnosed with Down's syndrome (age range $=2-6$ years) were matched for gender and age with five healthy comparison subjects. To analyse the overall and regional brain volumes, high-resolution MRI scans were performed and a morphometric analysis was conducted via MRI Studio software. The MRI T1 volumetric images were normalised using a linear transformation, which was followed by large deformation diffeomorphic metric mapping. Significant decreases $(p<0.05)$ in the volumes of the right pons, cerebellum and left superior frontal gyrus (prefrontal cortex) were observed in the children with DS when compared with the control group ( $\mathrm{p}<0.05$ ). Although decreases were detected in the regional volumes of other brain locations, they were not significant $(\mathrm{p}>0.05)$. It was further found that the developmental retardation observed in the children with DS, as detected using the Denver II test, increased due to decreases in the volumes of certain regions of the brain, although this was also not statistically significant $(\mathrm{p}>0.05)$. The results of this study generally confirm the findings of prior studies concerning the overall patterns of the brain volumes in children with DS and also provide new evidence of the abnormal volumes of specific regional tissue components among such a population. These results suggest that the brain volume reduction associated with DS may primarily be due to early developmental differences rather than neurodegenerative changes
\end{abstract}

Keywords: Down's syndrome, brain volume, MRI, Denver II test

\section{Introduction}

Down's syndrome (DS), which is one of the most common genetic causes of mental retardation, is a complex neurodevelopmental disorder characterized by language and memory deficits, low muscle tone, poor balance, decreased cognition, poor postural control, and an abnormal gait (Carducci et al., 2013; Gunbey et al., 2017; Anderson et al., 2013). The DNA sequence of chromosome 21 and the clinical features of DS have been characterized in the literature, with such reports describing the different neuropathological brain abnormalities associated with the syndrome (Anderson et al., 2013; Adeyemi et al., 2014)

Magnetic resonance imaging (MRI) studies have demonstrated significant reductions in the volumes of the cerebrum, brain stem and cerebellum in individuals with DS
(Carducci et al., 2013; Rigoldi et al., 2009). The impairments in the higher cognitive functions, such as cognitive planning and linguistic syntactic processing, typically seen in those with DS may be associated with the decreased cerebellar volume (Menghin et al., 2011). In addition to the total brain volume, the cingulate gyrus, frontal lobe, temporal lobe, hippocampi, grey matter in the inferior cerebellum and fusiform gyrus have similarly been found to be smaller in individuals with DS than in typically developing individuals (Anderson et al., 2013; Adeyemi et al., 2015; Rigoldi et al., 2009; Menghin et al., 2011).

Recently, the calculation of the volumes of the subcortical and cortical structures in the brain has become a popular field of research. There are several techniques available for the 
semi-automatic or automatic segmentation of the subcortical structures (Igual et al., 2011; Corson 1999; Ertekin et al., 2013), including FSL (Jenkinson et al., 2011). Analysis of Functional NeuroImages (AFNI) (Cox et al., 2011), Brain Voyager (Goebel et al., 2012), FreeSurfer (Fischl et al., 2012) and SPM (Ashburner et al., 2012), which have all been used to analyze the structural properties of the human brain by means of MRI. For instance, Guenette et al. (Guenette et al., 2018) and Jovicich et al. (Jovicich et al., 2009) used FreeSurfer, while Wang et al. (Wang et al., 2019) used volBrain. Kocaman et al. (Kocaman et al., 2019) and Palanc1 et al. (Palanc1 et al., 2018) used MRI-studio, while Mori et al. (Mori et al., 2016) used Acer and Turgut (Acer et al., 2018). Moreover, Rezende et al. (Rezende et al., 2019) used MRI Cloud to perform the required brain volume measurements.

MRI Studio is a valid and sophisticated program that is widely used in neuroimaging studies of both MRI and diffusion tensor imaging (DTI) data. Currently, MRI Studio consists of three programs, namely DTI Studio (Jiang et al., 2006), DiffeoMap and ROI Editor. DiffeoMap images the transformation based on the large deformation diffeomorphic metric mapping (LDDMM) process, while ROIEditor uses the DiffeoMap results to perform an image analysis concerning a single atlas at both the voxel and regional levels (Ceritoglu et al., 2013). Different methods have been used to estimate the brain volume in prior studies (Morey et al., 2009; Morey et al., 2010; Acer et al., 2017; Acer et al., 2018).

To the best of our knowledge, no previous studies have used MRI Studio in patients with Down's syndrome. Therefore, the aim of this study was to compare the brain structure volumes of children with DS to those of healthy children using MRI Studio in order to investigate whether there exists correlation between the developmental stages of DS and the results of both the Denver II Developmental Screening Test and MRI quantitative analysis.

\section{Materials and methods}

\subsection{Subjects}

The present study involved five children with DS (one boy and four girls; mean age $2.6 \pm 0.69$ years) and five healthy controls (two girls and three boys; mean age $2.5 \pm 0.707$ years). The study was approved by the Erciyes University Medical School Ethics Committee.

The five gene-positive subjects were enrolled in the study on the basis of their karyotype examination results. The control group comprised five right-dominant, age- and sexmatched healthy subjects who had been referred to our hospital for an MRI scan (for various reasons other than DS) and who had normal findings on the structural MRI. Chloral hydrate $(\mathrm{CH} ; 50 \mathrm{mg} / \mathrm{kg})$ was administered to the subjects prior to the MRI scan to provide sedation. The subjects' oxygen saturation and electrocardiogram levels were monitored throughout the period of sedation.
The Denver II Developmental Screening Test was used to assess the development of the DS group in terms of the personal, social, linguistic and motor areas as well as to determine their percentile. The data concerning the DS group were compared the data concerning healthy children of the same age (Yalaz et al., 2010).

\subsection{Histological procedure}

The lung tissues were a solution of $10 \%$ for two weeks. All samples underwent to routine tissue processing involved in dehydration, clearing, and embedding. The paraffin blocks were cut at $7 \mu \mathrm{m}$ thickness based on the systematic random sampling method using microtome (Leica RM2125RT, Leica Instruments, Germany). The sections were then mounted onto slides and then stained with triple.

\subsection{Electromagnetic field exposure system}

Procedure of this EMF exposure was according to our previous study (Ulubay et al., 2014). A $900 \mathrm{MHz}$ continuous wave electromagnetic energy generator was used with a peak specific absorption rate (SAR) of $2 \mathrm{~W} / \mathrm{kg}$ and an average power density of $1 \pm 0.4 \mathrm{~mW} / \mathrm{cm}^{2}$ (Koyu et al., 2005). This generator was manufactured by the Electromagnetic Compatibility Laboratory of Suleyman Demirel University. Estimation of Localized SAR values were done as described by Sirav and Seyhan (2011). We also measured the power density of EMF using an EMF meter (Holaday Industry Inc., Adapazar1, Turkey). The monopole antenna of the exposure system was located perpendicular in the center of the round plastic cage to ensure that electric field distributed uniformly (Koyu et al., 2005). A $1 \mathrm{~cm}$ diameter air holes was devised on the cage to attenuate stress in rats. Animals were arranged adjacent to each other at a $1 \mathrm{~cm}$ distance with their heads in direction of the antenna.

\subsection{Image acquisition}

All the images used in this study were obtained using an Aera 1.5T MRI Scanner (Siemens, The Netherlands). The thinsection MRI data were obtained using a T1-weighted 3D magnetization prepared rapid gradient echo (MPRAGE) sequence $(\mathrm{TR} / \mathrm{TE}=1900 / 2.84$; the data set contained an image matrix: $256 \times 256$ pixels $\times 160$ slices for a $\mathrm{FOV}=280 \times 280 \mathrm{~mm}$; matrix size $=256 \times 256$; flip angle $[\mathrm{FA}]=5^{\circ}$; number of slices $=160$ and slice thickness $=1.0$ $\mathrm{mm}$; NSA = 2).

\subsection{Atlas-based analysis using MRI Studio}

MRI Studio (DTI Studio, ROIEditor and DiffeoMap) software was used to process all the $\mathrm{T} 1$ datasets in this study (Mori et al., 2008). After stripping, we saved the images while applying a skull-stripped mask generated in ROIEditor. Then, each subject's masked images were used to perform the LDDMM (Miller et al., 2005, Oishi et al., 2009).

More specifically, each subject's masked images were first transformed linearly (using an automated image registration $[\mathrm{AIR}]$ transformation with trilinear interpolation) 
and then non-linearly (using LDDMM, with cascading alphas of $0.01,0.005$ and 0.002 ) in order to match as much as possible, the corresponding single-participant skull-stripped templates produced by Johns Hopkins University (JHU_MNI_T1_ss). Next, the inverse transformation algorithms (the inverse LDDMM and then the inverse AIR) were applied to the ROI atlas (JHU_MNI_SS_WMPM_TypeII) to determine the ROIs within each participant's original brain space, thereby leading to the parcellation of the brain into 181 anatomical structures. As a result, each participant's quantitative volume values (i.e., the number of voxels) for the 181 parcellated brain structures were obtained (Fig. 1) (Faria et al., 2010; Faria et al., 2011).

To ensure that the algorithms had been appropriately executed, the generated ROIs were visually observed to assess their accuracy. Then, the average caudate volume values of the ROIs were extracted using an ROI editor. Among the 181 parcellated brain structures, the total number of voxels of the two cerebellar regions (region no. 81, "cerebellum left"; region no. 82, "cerebellum right") was used to calculate the volume of the cerebellum.

\subsection{Statistical analysis}

To determine normality was used the Shapiro-Wilk test, and the Mann-Whitney $U$ test to comparisons of the means of variables with controls. Correlations between volumetric values and Denver II test were calculated with Spearman's correlation test. A p-value less than 0.05 was considered to indicate statistical significance.

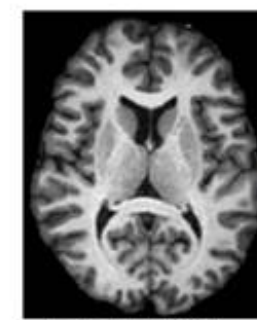

Tenolde JHU_WLISS.T1_s

Lineer transformation

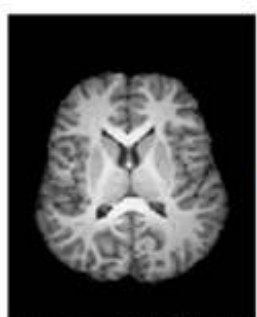

Subied madochiedtiling. 0
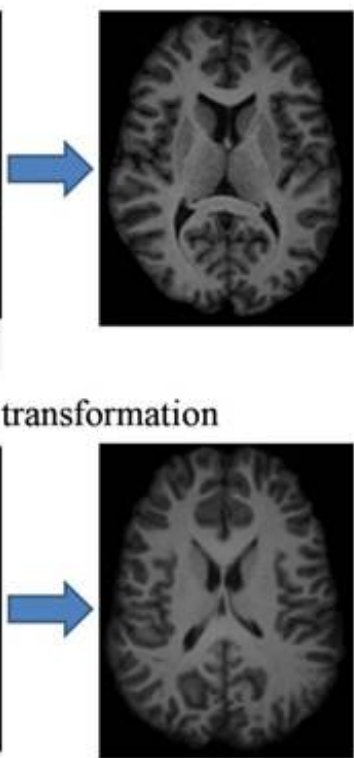

Fig. 1. A schematic diagram of the image normalization process using MRiStudio

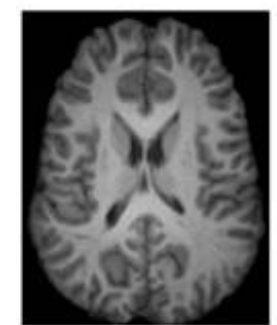

Updated maskObject

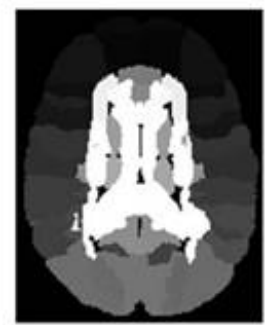

JHU BPM Type ॥

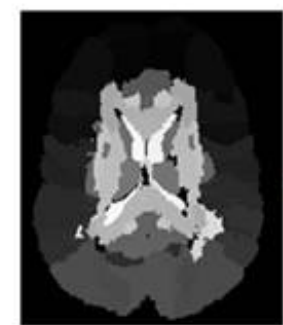

LDDMM_Post_Hmap

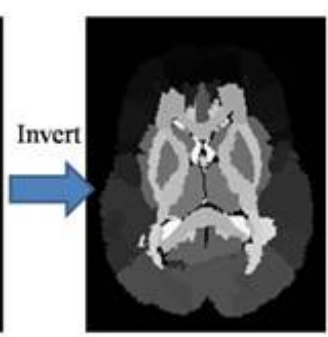

Updated_LDDMM

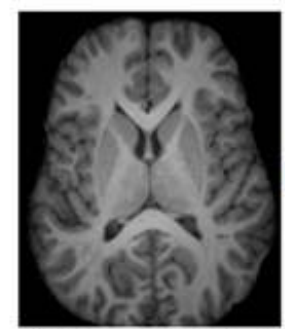

Original_T1 (Mask)

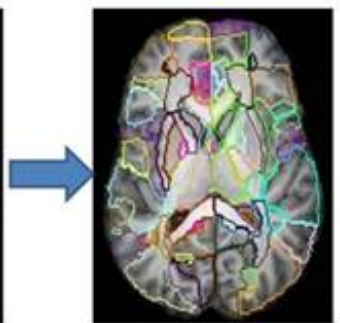

Superimposed LDDMM

\section{Results}

The present study included five children with DS (mean age $3.5 \pm 1.1$ years) and five healthy controls (mean age $3.1 \pm 1.8$ years). Significant decreases in the volumes of the left side of the superior frontal gyrus (prefrontal cortex), the pons and both sides of the cerebellum were found in the DS group $(p<$ 0.05). The volumes of the other structures (Table 1) and of the corpus callosum (Fig. 2) were also found to be lower in the DS group than in the control group, although the difference was not statistically significant $(p>0.05)$.

Based on the correlation between the brain structures of the individuals with DS and the results of the Denver II screening test, it was determined that the observed growth retardation was due to the identified volume shrinkage, although the difference was not statistically significant $(\mathrm{p}>$ 0.05) (Table 2).

\section{Discussion}

The principal findings of the present study are the significant decreases $(p<0.05)$ found in the volumes of the right pons, the cerebellum and the left superior frontal gyrus (prefrontal cortex) in the DS group when compared with the control group. The decreases detected in the regional volumes of the other brain locations were not significant.

The volumes of the cerebellum, whole brain, hippocampal structures and other regions of the brain are known to be decreased in children with DS. However, varying results have been found in relation to the lobes of the brain due to difficulties associated with the global assessment of structural and neuroanatomical brain aberrations (Carducci et al., 2013; Gunbey et al., 2017; Pinter et al., 2001). Different methodological approaches could explain the differing results of similar studies involving children with DS, including the age range of the sample, the number of cerebral areas analyzed, the number of participants and the resolution of the MRI data. The brains of children with DS show a smaller 
Oz et al. / J Exp Clin Med

whole-brain volume than the brains of typically developing children. This decreased brain volume results in cognitive impairments (e.g., language learning difficulties; memory, attention and executive functioning problems), sensory processing problems (e.g., proprioception) and motor control difficulties.

Table 1. Regional brain volumes of subjects with Down's syndrome versus control subjects $\left(\mathrm{cm}^{3}\right)$.

\begin{tabular}{|c|c|c|c|c|}
\hline Region & & $\begin{array}{l}\text { Down Group } \\
(\text { mean } \pm \text { SD) }\end{array}$ & $\begin{array}{l}\text { Control Group } \\
(\text { mean } \pm \text { SD) }\end{array}$ & p-value \\
\hline \multirow{2}{*}{ Precentral Gyrus } & $\mathrm{R}$ & $22176 \pm 10067$ & $32104 \pm 9415$ & 0.146 \\
\hline & $\mathrm{L}$ & $17129 \pm 8199$ & $27354 \pm 9561$ & 0.107 \\
\hline \multirow{2}{*}{ Postcentral Gyrus } & $\mathrm{R}$ & $16981 \pm 7069$ & $24918 \pm 7264$ & 0.118 \\
\hline & $\mathrm{L}$ & $17118 \pm 7915$ & $22907 \pm 6520$ & 0.242 \\
\hline \multirow{2}{*}{ Angular Gyrus } & $\mathrm{R}$ & $17363 \pm 6753$ & $26170 \pm 6155$ & 0.063 \\
\hline & $\mathrm{L}$ & $12828 \pm 5239$ & $16873 \pm 3228$ & 0.180 \\
\hline \multirow{2}{*}{$\begin{array}{l}\text { Supramarginal } \\
\text { Gyrus }\end{array}$} & $\mathrm{R}$ & $10385 \pm 4725$ & $16002 \pm 4886$ & 0.102 \\
\hline & $\mathrm{L}$ & $11249 \pm 5455$ & $16549 \pm 3216$ & 0.98 \\
\hline \multirow{2}{*}{$\begin{array}{l}\text { Superior frontal } \\
\text { gyrus (prefrontal } \\
\text { cortex) }\end{array}$} & $\mathrm{R}$ & $13132 \pm 4958$ & $20236 \pm 6685$ & 0.094 \\
\hline & $\mathrm{L}$ & $13652 \pm 5276$ & $22266 \pm 5362$ & $0.034^{*}$ \\
\hline \multirow{2}{*}{ Thalamus } & $\mathrm{R}$ & $5436 \pm 1998$ & $6702 \pm 1551$ & 0.623 \\
\hline & $\mathrm{L}$ & $5637 \pm 2310$ & $6821 \pm 1597$ & 0.373 \\
\hline \multirow{2}{*}{ Caudate Nucleus } & $\mathrm{R}$ & $2703 \pm 1328$ & $2611 \pm 530$ & 0.889 \\
\hline & $\mathrm{L}$ & $3113 \pm 1493$ & $2755 \pm 323$ & 0.614 \\
\hline \multirow{2}{*}{ Putamen } & $\mathrm{R}$ & $2722 \pm 690$ & $3455 \pm 801$ & 0.159 \\
\hline & $\mathrm{L}$ & $2757 \pm 889$ & $3385 \pm 780$ & 0.269 \\
\hline \multirow{2}{*}{ GI. Pallidus } & $\mathrm{R}$ & $747 \pm 265$ & $929 \pm 166$ & 0.231 \\
\hline & $\mathrm{L}$ & $724 \pm 296$ & $935 \pm 202$ & 0.226 \\
\hline \multirow{2}{*}{ Red nucleus } & $\mathrm{R}$ & $138 \pm 46$ & $198 \pm 47$ & 0.517 \\
\hline & $\mathrm{L}$ & $145 \pm 57$ & $209 \pm 58$ & 0.431 \\
\hline \multirow{2}{*}{ Substantia Nigra } & $\mathrm{R}$ & $303 \pm 129$ & $305 \pm 77$ & 0.251 \\
\hline & $\mathrm{L}$ & $256 \pm 93$ & $308 \pm 107$ & 0.341 \\
\hline \multirow{2}{*}{ Hippocampus } & $\mathrm{R}$ & $2392 \pm 855$ & $3005 \pm 709$ & 0.252 \\
\hline & $\mathrm{L}$ & $2702 \pm 929$ & $2819 \pm 626$ & 0.88 \\
\hline \multirow{2}{*}{$\begin{array}{l}\text { Para hippocampal } \\
\text { Gyrus }\end{array}$} & $\mathrm{R}$ & $1559 \pm 485$ & $1948 \pm 507$ & 0.251 \\
\hline & $\mathrm{L}$ & $1348 \pm 504$ & $1652 \pm 502$ & 0.369 \\
\hline \multirow[t]{2}{*}{ Amygdala } & $\mathrm{R}$ & $1485 \pm 535$ & $1528 \pm 373$ & 0.886 \\
\hline & $\mathrm{L}$ & $1430 \pm 609$ & $1443 \pm 425$ & 0.970 \\
\hline \multirow{2}{*}{ Insula } & $\mathrm{R}$ & $5274 \pm 1748$ & $4915 \pm 1599$ & 0.743 \\
\hline & $\mathrm{L}$ & $6091 \pm 2227$ & $5789 \pm 1948$ & 0.825 \\
\hline \multirow{2}{*}{ Midbrain } & $\mathrm{R}$ & $1699 \pm 593$ & $1992 \pm 516$ & 0.429 \\
\hline & $\mathrm{L}$ & $1340 \pm 411$ & $1738 \pm 498$ & 0.206 \\
\hline \multirow{2}{*}{ Pons } & $\mathrm{R}$ & $302 \pm 140$ & $530 \pm 181$ & 0.050 \\
\hline & $\mathrm{L}$ & $91 \pm 23$ & $200 \pm 62$ & $0.006^{* *}$ \\
\hline \multirow{2}{*}{ Medulla Oblongata } & $\mathrm{R}$ & $905 \pm 321$ & $1365 \pm 543$ & 0.142 \\
\hline & $\mathrm{L}$ & $663 \pm 231$ & $963 \pm 386$ & 0.175 \\
\hline \multirow{2}{*}{ Cerebellum } & $\mathrm{R}$ & $40582 \pm 16242$ & $67032 \pm 17521$ & $0.038^{*}$ \\
\hline & $\mathrm{L}$ & $43092 \pm 17697$ & $67398 \pm 15631$ & $0.050 *$ \\
\hline \multirow{2}{*}{ Hypothalamus } & $\mathrm{R}$ & $361 \pm 150$ & $429 \pm 101$ & 0.429 \\
\hline & $\mathrm{L}$ & $398 \pm 157$ & $436 \pm 52$ & 0.623 \\
\hline
\end{tabular}

The significantly hypoplastic cerebellar volume noted in the present study is consistent with the findings of prior neuroimaging studies (Gunbey et al., 2017), and it reflects the loss of the neocortical neuronal projections involved in the maintenance of the higher cognitive processes (Pinter et al.,
2001; Kates et al., 2002). Rigoldi et al. reported the strong relationship between a reduced cerebellar vermis volume and the quality of an individual's gait (Rigoldi et al., 2007). However, the cerebellum plays a major role in the regulation of proprioceptive motor control and motor learning, 
hypotonia, the alteration of motor coordination and speech disturbances, as verified by the work of Ilg et al. (Ilg et al., 2007). Problems associated with the cerebellum might affect an individual's emotional regulation, attention, working memory, executive control and language learning through the non-motor cortico-cerebellar and cerebellar-limbic circuits known to be involved in DS (Strick et al., 2009).

Boisgueheneuc et al. demonstrated that (i) the lateral and posterior portions of the left superior frontal gyrus are key components of the neural network associated with the working memory, (ii) the participation of this region in the working memory is triggered by the highest level of executive processing, and (iii) the left superior frontal gyrus is also involved in spatially oriented processing (Boisgueheneuc et al., 2006). Moreover, Bletsch et al. investigated the same region and noted the decreased volume of the superior frontal gyrus (Bletsch et al., 2008). A significant decrease in the volume of the left superior frontal gyrus was also noted in the present study. Cognitive impairment leading to problems with executive functioning, self-awareness and coordination could explain the decreased planning ability and inadequate functionality exhibited by individuals with DS (Goldberg et al., 2006).

In terms of the brainstem, the pons was associated with the greatest divergences between the children with DS and the children in the control group in the present study. Prior studies have also demonstrated the decreased volume of the brainstem and the pons in individuals with DS. Raz et al. reported more decreased volumes in relation to the ventral part of the pons in adult DS patients using MRI data (Raz et al., 1995), while Komaki et al. noted small pons volumes with regard to the mid-sagittal MRI findings concerning infants with DS (2-4 years old) (Komaki et al., 1999). This situation results in functional abnormalities in the oculomotor circuits of the cerebellum associated with nystagmus (\% 20) and, consequently, hearing loss has been reported in $38-78 \%$ of patients with DS (Riozen et al., 2003; Shott et al., 2001). Problems with the pons can cause central apnea due to functional abnormalities, and episodes of sleep apnea have been reported in individuals with DS. Physico-motor development (e.g., standing and walking abilities) is known to be delayed in children with DS who have a small cerebellar volume, which may subsequently result in a small pons (Fujii et al., 2017).

To the best of our knowledge, no volumetric studies have previously been conducted via MRI Studio in children with DS. MRI Studio is an atlas-based volumetry method that allows the observer to perform fully automatic segmentation using the software (Keller et al., 2012; Poretti et al., 2012). To segment the subcortical structures, semi-automatic methods have been suggested. Such methods involve knowledgedriven two-step algorithms (Igual et al., 2011). However, these segmentation methods pose certain problems due to the anatomical structures' spatial locations, intensities and relative spatial relations varying among different groups of subjects (Zhou et al., 2005).

It is important to note that the present study had a few limitations. First, the cognitive/motor functions of the patients were not evaluated and, second, the sample size was relatively small. Larger populations should be investigated in future studies to ensure more accurate statistical results are obtained.

In conclusion, this study describes the brain volume abnormalities observed in children with DS via MRI Studio. Our data provide further evidence of the decreased volumes of several brain structures in individuals with DS, with the identified decreases being found to be statistically significant in the case of the right pons, the cerebellum and the left superior frontal gyrus (prefrontal cortex). These findings suggest that the brain volume reduction associated with DS may be primarily due to early developmental differences rather than neurodegenerative changes.

\section{Conflict of Interest}

The authors declare that there are no conflicts of interest relevant to this study.

\section{Acknowledgements}

All procedures performed in studies involving human participants were in accordance with the ethical standards of the institutional and/or national research committee and with the 1964 Helsinki declaration and its later amendments or comparable ethical standards. Written consent was obtained from the participants as per Erciyes University Ethical Board regulations (2013/413). This study has been supported by Erciyes University Scientific Research Projects Coordination Unit under grant number 2013/4728.

\section{References}

1. Brantingham JW, Bonnefin D, Perle SM, Cassa TK, Globe G, Pribicevic M, Hicks M, Korporaal C. 2012. Manipulative therapy for lower extremity conditions: update of a literature review. J Manipulative Physiol. Ther. 35(2), 127-166.

2. Carducci. F, Onorati., P, Condoluci. C., Di Gennaro., G., Quarato. P.P., Pierallini., A., Sarà. M., Miano., S., Cornia., R., Albertini., G. 2013. Whole-brain voxel-based morphometry study of children and adolescents with Down syndrome. Funct. Neurol. 28(1), 19-28.

3. Gunbey, H.P., Bilgici, M.C., Aslan, K., Has, A.C., Ogur, M.G., Alhan, A., Incesu, L., 2017. Structural brain alterations of Down's syndrome in early childhood evaluation by DTI and volumetric analyses. Eur. Radiol. 7(7), 3013-3021.

4. Anderson, J.S., Nielsen, J.A., Ferguson, M.A., Burback, M.C., Cox, E.T., Dai, L, Gerig, G., Edgin, J.O., Korenberg, J.R. 2013. Abnormal brain synchrony in Down Syndrome. Neuroimage Clin. 24(2),703-715.

5. Adeyemi, E.I., Giedd, J.N., Lee, N.R. 2015. A case study of brain morphometry in triplets discordant for Down syndrome. Am. J. Med. Genet. A. 167A (5), 1107-1110.

6. Rigoldi, C., Galli, M., Condoluci, C., Carducci, F., Onorati, P., Albertini, G. 2009. Gait analysis and cerebral volumes in Down's 
syndrome. Funct. Neurol. 24(3):147-152.

7. Menghini, D., Costanzo, F., Vicari, S. 2011. Relationship between brain and cognitive processes in Down syndrome. Behav. Genet. 41(3):381-393.

8. Igual, L., Soliva, J.C., Hernández-Vela, A., Escalera, S., Jiménez, X., Vilarroya, O., Radeva, P. 2011. A fully-automatic caudate nucleus segmentation of brain MRI: Application in volumetric analysis of pediatric attention-deficit/hyperactivity disorder. Biomed. Eng. Online. 10, 105.

9. Corson, P.W., Nopoulos, P., Miller, D.D., Arndt, S., Andreasen, N.C. 1999. Change in Basal Ganglia Volume Over 2 Years in Patients with Schizophrenia: Typical Versus Atypical Neuroleptics. Am. J. Psychiatry. 156, 1200-1204.

10. Ertekin, T., Acer, N., İçer, S., Ilıca, AT. 2013. Comparison of two methods for the estimation of subcortical volume and asymmetry using magnetic resonance imaging: a methodological study. Surg. Radiol. Anat. 35, 301-309.

11. Jenkinson, M., Beckmann, C.F., Behrens, T.E., Woolrich, M.W., Smith, S.M. FSL. 2012. Neuroimage. 62, 782-790.

12. Cox, R.W. 2012. AFNI: What a long strange trip it's been. Neuroimage. 62, 743-747.

13. Goebel R. 2012. BrainVoyager-past, present, future. Neuroimage. $62,748-756$.

14. Fischl., B. 2012. FreeSurfer. Neuroimage. 62, 774-781.

15. Ashburner, J. 2012. SPM: A history. Neuroimage. 62, 791-800.

16. Guenette, J.P., Stern, R.A., Tripodis, Y., Chua, A.S., Schultz, V., Sydnor, V.J., Somes, N., Karmacharya, S., Lepage, C., Wrobel, P., Alosco, M.L., Martin, B.M., Chaisson, C.E., Coleman, M.J., Lin, A.P., Pasternak, O., Makris, N., Shenton, M.E., Koerte, I.K. 2018. Automated versus manual segmentation of brain region volumes in former football players. Neuroimage Clin. 18, 888896.

17. Jovicich, J., Czanner, S., Han, X., Salat, D., van der Kouwe, A., Quinn, B., Pacheco, J., Albert, M., Killiany, R., Blacker, D., Maguire, P., Rosas, D., Makris, N., Gollub, R., Dale, A., Dickerson, B.C., Fischl, B. 2009. MRI-derived measurements of human subcortical, ventricular and intracranial brain volumes: Reliability effects of scan sessions, acquisition sequences, data analyses, scanner upgrade, scanner vendors and field strengths. Neuroimage. 46 (1), 177-192.

18. Wang, Y., Xu, Q., Luo, J., Hu., M., Zuo, C. 2019. Effects of Age and Sex on Subcortical Volumes. Front Aging Neurosci. 11, 259.

19. Kocaman, H., Acer, N., Köseoğlu, E., Gültekin, M., Dönmez, H. 2019. Evaluation of intracerebral ventricles volume of patients with Parkinson's disease using the atlas-based method: A methodological study. J. Chem. Neuroanat. 98, 124-130.

20. Palancı, Ö., Kalaycıoğlu, A., Acer, N., Eyüpoğlu, İ., Çakmak, V. 2018. Volume Calculation of Brain Structures in Migraine Disease by Using MriStudio. NeuroQuantology. 16(10), 8-13.

21. Mori S., 2016. MRICloud: Delivering High-Throughput MRI Neuroinformatics as Cloud-Based Software as a Service. Comput. Sci. Eng. 18(5), 21-35.

22. Acer, N., Turgut, M. 2018. Measurements of the Insula Volume Using MRI. In: Turgut, M., Yurttaş, C., Shane Tubbs, R. editors. Island of Reil (Insula) in the Human Brain. Springer International Publishing AG, part of Springer Nature. 101-111.

23. Rezende, T.J.R., Campos, B.M., Hsu, J., Li, Y., Ceritoglu, C., Kutten, K., França, Junior M.C., Mori, S., Miller, M.I., Faria, A.V. 2019. Test-retest reproducibility of a multi-atlas automated segmentation tool on multimodality brain MRI. Brain. Behav. 9
(10), e01363.

24. Jiang, H., van Zijl, P.C., Kim, J., Pearlson, G.D., Mori, S. 2006. DtiStudio: resource program for diffusion tensor computation and fiber bundle tracking. Comput. Methods Programs Biomed. 81(2), 106-116.

25. Ceritoglu, C., Tang, X., Chow, M., Hadjiabadi, D., Shah, D., Brown, T., Burhanullah, M.H., Trinh, H., Hsu, J.T., Ament, K.A., Crocetti, D., Mori, S., Mostofsky, S.H., Yantis, S., Miller, M.I., Ratnanather, J.T. 2013. Computational analysis of LDDMM for brain mapping. Front. Neurosci. 27(7), 151.

26. Morey, R.A., Petty, C.M., Xu, Y., Hayes, J.P., Wagner, H.R., Lewis, D.V., LaBar, K.S., Styner, M., McCarthy, G. 2009. A comparison of automated segmentation and manual tracing for quantifying hippocampal and amygdala volumes. Neuroimage. $45(3), 855-866$.

27. Morey, R.A., Selgrade, E.S., Wagner, H.R., Huettel, S.A., Wang, L., McCarthy, G. 2010. Scan-rescan reliability of subcortical brain volumes derived from automated segmentation. Hum. Brain. Mapp. 31(11), 1751-1762.

28. Acer., N, Dolu., N, Zararsiz., G, Dogan, M.S, Gumus K, Ozmen S. 2017. Anatomical characterization of ADHD using an atlasbased analysis: A diffusion tensor imaging study. The Eurobiotech. J. 1, 46-56.

29. Acer, N., Bastepe-Gray, S., Sagiroglu, A., Gumus, K.Z., Degirmencioglu, L, Zararsiz, G, Ozic., M.U. 2018. Diffusion tensor and volumetric magnetic resonance imaging findings in the brains of professional musicians. J. Chem. Neuroanat. 88, 3340.

30. Yalaz, K., Anlar, B., Bayoğlu, B. Denver II Gelişimsel Tarama Testi Türkiye Standardizasyonu. Denver II Developmental Screening Test Handbook. Ankara: Anıl Grup Matbaacılık; 2010.

31. Mori, S., Oishi, K., Jiang, H., Jiang, L., Li, X., Akhter, K., Hua, K., Faria, A.V., Mahmood, A., Woods, R., Toga, A.W., Pike, G.B., Neto, P.R., Evans, A., Zhang, J., Huang, H., Miller, M.I., van Zijl, P., Mazziotta, J. 2008. Stereotaxic white matter atlas based on diffusion tensor imaging in an ICBM template. Neuroimage. 40 (2), 570-582.

32. Miller, M.I., Beg, M.F., Ceritoglu, C., Stark, C. 2005. Increasing the power of functional maps of the medial temporal lobe by using large deformation diffeomorphic metric mapping. Proc. Natl. Acad. Sci. USA. 102 (27), 9685-9690.

33. Oishi, K., Faria, A., Jiang, H., Li, X., Akhter, K., Zhang, J., Hsu, J.T., Miller, M.I., van Zijl, P.C., Albert, M, Lyketsos, C.G., Woods, R., Toga, A.W., Pike, G.B., Rosa-Neto, P., Evans, A., Mazziotta, J., Mori, S. 2009. Atlas-based whole brain white matter analysis using large deformation diffeomorphic metric mapping: application to normal elderly and Alzheimer's disease participants. Neuroimage. 46 (2), 486-499.

34. Faria, A. V., Hoon, A., Stashinko, E., Li, X., Jiang, H., Mashayekh, A., Akhter, K., Hsu, J., Oishi, K., Zhang, J., Miller, M. I., van Zijl, P. C., \& Mori, S. 2011. Quantitative analysis of brain pathology based on MRI and brain atlases--applications for cerebral palsy. NeuroImage. 54 (3), 1854-1861.

35. Faria AV, Zhang J, Oishi K, Li X, Jiang H, Akhter K, Hermoye L, Lee SK, Hoon A, Stashinko E, Miller MI, van Zijl PC, Mori S. 2010. Atlas-based analysis of neurodevelopment from infancy to adult hood using diffusion tensor imaging and applications for automated abnormality detection. Neuroimage. 52 (2), 415-428.

36. Pinter, J.D., Eliez, S., Schmitt, J.E., Capone, G.T., Reiss, A.L. 2001. Neuroanatomy of Down's syndrome: A high-resolution MRI study. Am. J. Psychiatry. 158(10),1659-1665.

37. Kates, W.R., Folley, B.S., Lanham, D.C., Capone, G.T., 
Kaufmann, W.E. 2002. Cerebral growth in Fragile X syndrome: review and comparison with Down syndrome. Microsc. Res. Tech. 57(3), 159-167.

38. Rigoldi, C., Galli, M., Condoluci, C., Carducci, F., Onorati, P., Albertini G. 2009. Gait analysis and cerebral volumes in Down's syndrome. Funct. Neurol. 24(3), 147-152.

39. Ilg, W., Golla, H., Their, P, Giese MA., 2007. Specific influences of cerebellar dysfunctions on gait. Brain. 130 (3), 786798.

40. Strick, P.L., Dum, R.P., Fiez, J.A. 2009. Cerebellum and nonmotor function. Annu. Rev. Neurosci. 32, 413-434.

41. du Boisgueheneuc, F., Levy, R., Volle, E., Seassau, M., Duffau, H., Kinkingnehun, S., Samson, Y., Zhang, S., Dubois, B. 2006. Functions of the left superior frontal gyrus in humans: a lesion study. Brain. 129 (12), 3315-3328.

42. Bletsch, A., Mann, C., Andrews, D.S., Daly, E., Tan, G.M.Y., Murphy, D.G.M., Ecker, C. 2018. Down syndrome is accompanied by significantly reduced cortical grey-white matter tissue contrast. Hum. Brain Mapp. 39(10), 4043-4054.

43. Goldberg II, Harel M, Malach R. When the brain loses its self: prefrontal inactivation during sensorimotor processing. 2006. Neuron. 50(2), 329-339.

44. Raz, N., Torres, I.J., Briggs, S.D., Spencer, W.D., Thornton, A.E., Loken, W.J., Gunning, F.M., McQuain, J.D., Driesen, N.R., Acker, J.D. 1995. Selective neuroanatomic abnormalities in
Down's syndrome and their cognitive correlates: evidence from MRI morphometry. Neurology. 45(2), 356-366.

45. Komaki, H., Hamaguchi, H., Hashimoto, T. 1999. Assessment of the brainstem and the cerebellar lesions and myelination using magnetic resonance images in children with Down syndrome. No To Hattatsu. 31(5), 422-427.

46. Roizen, N.J, Patterson, D., 2003. Down's syndrome. Lancet. 361(9365), 1281-1289.

47. Shott, S.R., Joseph, A., Heithaus, D., 2001. Hearing loss in children with Down syndrome. Int. J. Pediatr. Otorhinolaryngol. 61(3),199-205.

48. Fujii, Y., Aida, N., Niwa, T., Enokizono, M., Nozawa, K., Inoue, T., 2017. A small pons as a characteristic finding in Down syndrome: A quantitative MRI study. Brain Dev. 39(4), 298-305.

49. Keller, S. S., Gerdes, J. S., Mohammadi, S., Kellinghaus, C., Kugel, H., Deppe, K., Ringelstein, E. B., Evers, S., Schwindt, W., Deppe, M. 2012. Volume estimation of the thalamus using freesurfer and stereology: consistency between methods. Neuroinformatics. 10(4), 341-350.

50. Poretti, A., Mall, V., Smitka, M., Grunt, S., Risen, S., Toelle, SP. 2012. Macrocerebellum: Significance and pathogenic considerations. Cerebellum. 11(4), 1026-1036.

51. Zhou, J., Rajapakse, J.C., 2005. Segmentation of subcortical brain structures using fuzzy templates. Neuroimage. 28, 915-924. 